proposals for public works in relief of unemployment were argued only in terms of finance. They gibbet the May Report of 1931 which decided, for example, that Britain could not afford $£ 1 \frac{1}{2}$ million a year for extended services to reduce maternal mortalitya sum we now spend in three hours of war.

This book is designed to help the common man to face the fact of revolution in reproduction, for in the long run, as the authors afirm in their final chapter, "The People Must Decide".

\section{SCIENCE IN SOVIET RUSSIA}

\section{Science in Soviet Russia}

By Seven British Scientists. Edited by Dr. Joseph Needham and Jane Sykes Davies. Pp. v+65. (London: Watts and Co., Ltd., 1942.) 1s, $3 d$. net.

7 HIS little book provides a most useful glimpse of some of the scientific developments which have contributed towards the prodigious effort of defence by the Soviet Union in the present War.

The strength of science in the U.S.S.R. is based on its position in the official ideology. It is believed that a correct outlook on life and an adequate standard of living involves science as an integral part of all activities, spiritual and temporal. Hence science has been connected with every aspect of life, and its position in the Soviet State might be compared with that of the nervous system in man. As a result of these ideas, immense sums have been spent on laboratories and the training of scientific workers, and developments have been made according to plans. The scientific part of the new social order is in the main only fifteen to twenty years old. It has produced tens of thousands of new young scientific workers, many of them somewhat raw and not yet old enough in tradition to have highly developed scientific intuitions and critical judgments, but superb material for flying and artillery officers and factory management.

The events of the War have driven the chief Allied nations to create scientific organizations which grow more and more similar to the Soviet system of planned science. For this reason, as well as the bare facts, the seven essays in this book are of interest. Dr. Shoenberg's essay on physical research in the Soviet Union is outstanding. He speaks Russian, and has had the opportunity of working in Prof. P. Kapitza's laboratories in both Cambridge and Moscow. His comparative study of the two experiences is most illuminating. He says that the Moscow institute is several times larger, and has pleasant grounds. It has a staff of sixty people, compared with ten in the Mond Laboratory. For each physicist in the Soviet laboratory there are ten other employees, while at Cambridge there is only one. Half of the sixty are janitors, charwomen, chauffeurs, boilermen, gardeners, etc. Ten are oifice workers, and there was a good deal of. 'red tape'. The ratio of mechanics and technicians to physicists was about four times as great as in England. Dr. Shoenberg found this a real boon. They were first-rate craftsmen, and so released much more of the physicist's time for attention to real physical problems.

Another attractive feature is that the research worker belongs to a particularly respected profession, and is not liable, as in pre-war England, to be asked: 'But what do you do for a living?"
Dr. Ruhemann writes on industrial research from his six years' experience at Kharkov, Dr. Needham reviews work in biology, Dr. Walton agricultural rosearch, Mr. Roscoe Clarke developments in medicine, and Dr. G. W. Tyrrell the growth of geology and mineralogy.

It is all informative, and is very reasonably priced. J. G. Crowther.

\section{LINEAR DIFFERENTIAL EQUATIONS}

\section{Operational Methods in Applied Mathematics}

By Prof. H. S. Carslaw and J. C. Jaeger. Pp. xvi+264. (Oxford: Clarendon Press; London: Oxford University Press, 1941.) 17s. 6d. net.

W WAY to solve linear differential equations by A operational methods which avoid the introduction of arbitrary constants by taking direct account of the initial conditions was invented by Oliver Heaviside (1850-1925) for the purpose of discussing electromagnetic waves. In his hands the method led to correct results, but the mathematical foundation was so obscure as to cause it to be regarded with misgiving. Bromwich (1875-1930) was the first to explain Heaviside's method, and, by expressing the solution in the form of a contour integral, to justify its application to ordinary linear equations. Since then many systems, modifications and expositions of varying degrees of merit have appeared.

The present work is based on the application of the Laplace transform

$$
\bar{x}(p)=\int_{0}^{\infty} e^{-p t} x d t,
$$

where $p$ is a positive number sufficiently large to ensure the convergence of the integral and $x$ is a given function of $t$. Thus, if $x=e^{a t} . \bar{x}^{\prime}(p)=1 /(p-a)$. To take a very simple illustration, consider the equation $d x / d t+3 x=e^{-2 t}$, given that $x=0$ when $t=0$. Multiply by $e^{-p t}$ and integrate from 0 to $\infty$. This gives:

$$
x(p)=\int_{0}^{\infty} e^{-p t} x d t=\frac{1}{p+2}-\frac{1}{p+\overline{3}},
$$

so that $x=e^{-2 t}-e^{-3 t}$.

It will be seen from the above that the solution is inferred by writing down the function $x$ whose Laplace transform is given, that is, by inverting the transform. In simple cases this can be done by inspecting a list or dictionary of transforms (such a list is given at the end of the book). When inspection fails, the inversion can be effected by a general theorem which expresses $x$ as a contour integral when $\vec{x}(p)$ is given. Thus the method is direct, simple to apply and easy to understand.

The book contains three purely mathematical chapters on the application of the Laplace transform to linear equations with constant coefficients, on the inversion theorem, and on linear partial differential equations. The remaining seven chapters, each complete in itself, discuss a varied and interesting collection of problems in electric circuit theory, dynamics, conduction of heat, vibrations of continuous systems, hydrodynamics, electric transnission lines, electric waves. There are also numerous exercises for the student.

The book is well written, well printed, and can be recommended unreservedly to all who have to make scientific applications of linear differential equations. L. M. Munne-Thomson. 